Index Copernicus Value: 83.27

ISSN (e)-2347-176x ISSN (p) 2455-0450

crossref DOI: _http://dx.doi.org/10.18535/jmscr/v4i8.59

\title{
Oral Manifestation of Respiratory Disorder -A Review
}

\author{
Author \\ Aishwarya.J \\ IV BDS, Saveetha Dental College \\ 142-D, Alex Street, Panneer nagar phase 2, Mogappair east, Chennai-37 Tamil Nadu, India \\ Email:aishu8295@gmail.com
}

\begin{abstract}
Many pulmonary disorders like respiratory obstructive diseases, systemic diseases with pulmonary involvement, lung cancer, cystic fibrosis or tuberculosis all have clinical and or therapeutic involvement of the oral cavity, which underlines the necessity of regular dental services and careful oral cavity exam, as well as an active collaboration between dental practitioners and pulmonologists. The main objective of this review is to create awareness among the dental professionals about the various oral manifestations of respiratory disorders, so that they diagnose it in a much earlier stages, for patient's ultimate benefit

KEY WORDS: Pulmonary disorders, dental service, oral cavity,
\end{abstract}

\section{INTRODUCTION}

Oral diseases such as dental caries, periodontal disease, tooth loss, oral mucosal lesions and oropharyngeal cancers, human immunodeficiency virus/acquired immunodeficiency syndrome (HIV/AIDS)-related oral disease and orodental trauma are major public health problems worldwide and poor oral health has a profound effect on general health and quality of life ${ }^{(1)}$. Many systemic diseases and conditions manifest themselves initially in the mouth. Therefore, early diagnosis by a dental professional can lead to early referral to the appropriate health professional (2). There is an anatomical connection between the oral cavity and lungs, and so the oral cavity serves as a potential reservoir of the respiratory pathogens. These pathogens should defeat the immunological and mechanical defense mechanism to reach the lower respiratory tract.
The body's defense mechanism is efficient enough to defeat these pathogens from entering the respiratory tract. This is the reason why healthy individuals are not affected in spite of the heavy bacterial load found in the oral reservoir and upper respiratory tract ${ }^{(3)}$. Most often examination of the oral cavity in cases of pulmonary diseases is neglected. The oral cavity will help in the clinical diagnosis of the pulmonary diseases ${ }^{(4)}$.

\section{BACTEREMIA}

In dental procedures like extraction, $3^{\text {rd }}$ molar surgeries, endodontic treatments, periodontal surgeries, root scaling the presence of bacteremia is studied ${ }^{(5,6,7,8,9,10,11,12,13,14)}$. In these procedures the dissemination of oral pathogens into the blood stream is common. From the blood stream it enters the vital organs like lungs etc. ${ }^{(15)}$ 
In a normal scenario, the oral cavity surface contains a lot of microorganism, but the underlying tissues and blood stream is sterile. This is because of the three barrier mechanism such as physical, electrical and immunological barriers our body has. Physically the oral cavity prevents the entry of plaque pathogens with the help of epithelium, the electrical barrier that reflects $E_{h}$ difference between the host cells and the micro organism, immunologically the reticuloendothelial system helps in the formation of barrier against

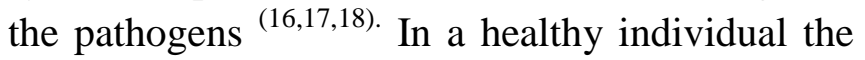
three barriers works in harmony and defends the pathogens from entering the blood stream, but in conditions in which the barriers are affected like trauma which destroy the physical barriers , hypoxia which destroys the electrical barrier, and immune suppressive conditions which affects the immunological barrier. These injuries will disturb the equilibrium and paves way for the bacterial entry into the blood stream ${ }^{(19) .}$

\section{MECHANISM OF SPREAD OF INFECTION}

The spread of infection occurs in two ways hematogenous spread and through aspiration. Hematogenous spread of bacteria occurs after dental treatment which may include simple prophylactic procedures, but in this cases the primary source of infection is the periodontal anaerobic bacteria(20,21). Aspiration of the materials from the upper respiratory tract occurs in $45 \%$ of the individuals who are healthy during their sleep and it occurs in $70 \%$ of people with impaired consciousness ${ }^{(22)}$. Aspiration occurs in three ways , i)through the periodontal disease or poor oral hygiene which may lead to increased concentration of bacteria in the saivs, which then gets aspirated into the lungs stimulating the immune defence, ii) in some specific conditions the plaque present in the oral cavity may serve as a harbor for the the colonies of pulmonary pathogens and promotes their growth, iii) periodontal pathogens facilitates colonization of pulmonary pathogens in the upper respiratory tract (23).

\section{PULMONARY DISEASES AND ITS ORAL MANIFESTATIONS \\ CHRONIC OBSTRUCTIVE PULMONARY DISEASE}

The American thoracic society defines COPD as a disease state characterized by the presence of air flow obstruction either due to chronic bronchitis or emphysema, the air flow obstruction is generally progressive may be accompanied by airway hyperactivity and may be partially reversible ${ }^{(24)}$. It is a slow progressive disease that causes loss of lung function gradually (25). Smoking attributes to about $87 \%$ to $91 \%$ for the development of COPD ${ }^{(26)}$. In the recent years many researches and reviews has proposed the association between COPD and periodontitis (27, 28, 29, and 30). Other studies have shown association between periodontitis and COPD but only clinical parameters were used in those studies ${ }^{(31,32)}$. A study by Leuckfeld et al ${ }^{(33)}$ has proven the association, with a sign of marginal bone loss in the radiograph. The chronic marginal periodontitis is a progressive destructive disease, which affects the supporting structures of the teeth, and also the jaw bones. The other common manifestations are oral thrush, which is the most common mucosal ailment, dental plaque, gingival bleeding, pocket depth, tooth loss or sometimes toothlessness also occurs ${ }^{(34,35, \text { and } 36)}$. Wang et al ${ }^{(36)}$ compared the control group with the COPD patients with fewer remaining teeth of which some of them represented current smokers and some represented former smokers. These patients also developed plaque biofilm on their dentures, the plaque will act as a reservoir of the pathogens for the upper and lower airways ${ }^{(37)}$. In some cases the patients were exposed to increased risk of tobacco related cancers like cancers of the oral cavity, tongue ${ }^{(38)}$, Leukoplakia and erythroplakia ${ }^{(25) .}$

\section{TUBERCULOSIS}

Tuberculosis (TB) is a chronic infectious granulomatous disease caused mainly by Mycobacterium tuberculosis, an acid-fast bacillus that is transmitted primarily through the 
respiratory route through inhalation of infected airborne droplets containing the bacillus, $\mathrm{M}$. tuberculosis. Less commonly, TB is caused by exposure to Mycobacterium bovis through ingestion of unpasteurized, infected cow's milk or other atypical mycobacteria ${ }^{(39)}$. Oral lesions are seen in 0.05 to $5 \%$ of the patients with $\mathrm{TB}$ and may be either primary or secondary ${ }^{(40)}$. Primary oral tuberculosis is commonly observed in young age individuals. Whereas secondary form can involve any age groups; however middle and old age groups are commonly involved, having oral manifestations which are almost always painful (41). Oral manifestations can be in the form of ulcers, nodules, fissures, or tuberculomas that can be single or multiple, painless or painful principally affecting tongue and hard palate ${ }^{(40)}$. Pathogenesis of the oral tuberculosis is self inoculation with infected sputum, the patient with pulmonary tuberculosis usually have cough with sputum . so when the patient coughs the infected sputum gets lodged into the oral cavity, in normal conditions they do not cause any manifestations because it is protected by the oral epithelium, but when there is any injury to the mucosa or if there is any ulceration the protective barrier gets lost . when the protective layer is lost the bacteria easily enters and causes manifestations ${ }^{(40,41,42)}$. Mouth involvement in secondary tuberculosis is usually a result of reactivation and hematogenous spread from the primary infection of the lung, the lesions being very similar to those of a squamous cell carcinoma: irregular ulcerations with peripheral thickening and dirty-appearing base, biopsy and culture being necessary to confirm the granulomatous inflammation. Secondary oral tuberculosis usually leads to the diagnosis of asymptomatic pulmonary tuberculosis $(43,44,45)$

A case has been reported, in which 17 years old female patient was diagnosed with pulmonary tuberculosis, with the sign of palatal perforation. But usually, severe symptoms are seen only in older age groups and in secondary tuberculosis, in this case in it has occurred in younger age group and in primary tuberculosis. The ulcerations that has been reported in this case was soo deep that it caused palatal bone perforation ${ }^{(46)}$.

Another case of 45 year old female patient with ulcerations in the gums have been reported, in this case patient had family history of $\mathrm{Tb}$ and personal history of smoking. Patient had chronic ulcerations in the gingival for four months and also a single ulcer was present in the palatal mucosa. ${ }^{(47)}$

The clinical criteria for diagnosis of oral lesions such as (i) tuberculous ulcers, which consists of stellate ulcer, undermined edges, a granulating floor, ragged and not indurated. It is often painful. The tongue is the most commonest site for oral tuberculous lesions, they may also occur on the gingiva, floor of mouth, palate, lips and buccal mucosa. (ii) Oral carcinoma included a nonhealing ulcero-proliferative growth with pain, tenderness, limitation or loss of function, bleeding, red, white or mixed red and white areas. It can be flat or elevated. It may covered by necrotic slough. On palpation it can be smooth, granular, rough or crusted with induration of the base and margins. Presence of cervical lymphadenopathy. The lymphnodes are enlarged it is firm to hard on palpation usually non-tender unless secondarily infected and is fixed to the underlying structures. (iii) Periosteal tuberculosis, a piece of bone becomes dead (sequestrum) and remains within the cavity which is formed by destruction of the bone due to the infection commonly affecting long bones. This cavity is generally connected outside through a sinus. The cavity contains serous fluid and pus, which may be discharged through the sinus. The mouth of the sinus shows sprouting granulation tissue, which indicates presence of the sequestrum in depth. On palpation, the bone becomes thick and irregular. $\mathrm{X}$-ray shows areas of bony rarefaction surrounded by dense sclerosis and sometimes sequestrum within the cavity of the bone. ${ }^{(48)}$

\section{CYSTIC FIBROSIS}

Cystic fibrosis is a genetic disorder caused by mutations in the gene for the cystic fibrosis 
transmembrane conductance regulator (CFTR) protein, affecting mostly the respiratory tract, with chronic cough and sputum, dyspnea, recurrent infections, and associated pancreatic insufficiency and malnutrition ${ }^{(49)}$. Oral manifestations of cystic fibrosis include tooth discoloration, Salivary gland enlargement, increased risk of caries, colonization of bacteria and dental malocclusions ${ }^{(50)}$.

Tooth discolorations and hypolplastic defects of the permanent teeth have been reported by Swallow et al. $1967^{(51)}$ Jagels and Sweeney 1976 (52). The discoloration and the defects can be due to tetracycline intake during the period of development of permanent dentition, later the drugs were replaced because of its adverse effects which causes reduction in the involvement of hard tissue. Cystic fibrosis usually affects the mucous glands, so the most commonly affected salivary glands are sublingual and submandibular salivary glands. Of which the sublingual glands are completely made up of mucous acini and so they are more affected when compared the submandibular glands which consists of both serous and mucous acini. The parotid glands are not much affected because they are primarily made up of serous glands, CF does not affect the serous gland ${ }^{(53,54)}$. Disruption of normal parenchymal architecture is evident with distended acini and loss of distinguishing cellular morphology. The acinar lumina and ducts of both the sublingual and submandibular glands often are clogged with cellular debris and fine filaments. The pathological changes noted in these glands would appear to be associated principally with ductal obstruction, although some may be secondary to the disease process itself. In saliva the calcium content is increased, and there is a modification in the $\mathrm{pH}$ and buffering capacity $(55,56)$. The incidence of caries have been reduced in children with $\mathrm{CF}$, inspite of high intake of foods containing sugars ${ }^{(57)}$. This is because of the fact that these children are on antibiotics which prevents the development of caries, plaque and gingivitis and also the alteration in the $\mathrm{pH}$ an buffering capacity has an added effect on the remineralization of the tooth, but these patients have high incidence of calculus ${ }^{(58,59)}$. CF patients act as carriers of Pseudomonas aeruginosa in the pharynx, dorsum of the tongue buccal mucosa and in saliva ${ }^{(60)}$ this bacteria servers as the source of pulmonary infection in high risk patients ${ }^{(50)}$. Also this bacteria shows resistance against chlorhexidine. Patients with cystic fibrosis tends to have chronic nasal and sinus obstruction so they develop mouth breathing habits. Mouth breathing habits leads to open bite. So CF patients develop malocclusion ${ }^{(61)}$

\section{ASTHMA}

Asthma is a chronic respiratory disease associated with airway obstruction, with recurrent attack of paroxysomal dyspnea, and wheezing due to spasmodic contraction of the bronchi ${ }^{(62)}$. It is the most common respiratory disorder. It is often associated with dental cavities, erosions, periodontal disease and oral candidiasis ${ }^{(63)}$. In asthmatic patient due to the intake of Betaagonists salivary secretion will be reduced which is the defensive barrier protecting the oral environment ${ }^{(64,65)}$. Mostly the asthmatic patients will have mouth breathing habits and so because of that there will be dryness of the alveolar mucosa, which leads to the development of gingival inflammation ${ }^{(66)}$. Studies have shown that pathogens which are associated with the development of periodontal diseases like gingivitis and periodontitis play a protective role against the development of allergy which is the prominent feature of asthma ${ }^{(67) .}$ Card et al ${ }^{(68)}$ in his studies showed that the hyperresponsiveness produced by the allergen is decreased with the pesencde of the infection with Porphyromonas gingivalis after sensitization with the allergen. The third National Health And Nutrition Examination Survey (NHANES) has also reported the impotance of the colonization of oral pathogens like P.gingivalis which is reflected by the higher titres of $\mathrm{IgG}$ against P.gingivalis. which is associated with the decrease in the prevalence of asthma ${ }^{(69)}$ 


\section{PNEUMONIA}

Pneumonia is an infection in the lung parenchyma caused by the wide variety of microorganisms that includes bacteria, virus, fungi and parasites ${ }^{(70)}$. Pneumonia is of two types community acquired and hospital acquired. The lung consists of numerous units formed by progressive branching of airway. The lower respiratory tract is usually maintained sterile in spite of the fact that the secretions from the upper respiratory tract consists of heavy contamination with oral and nasal pathogens. The pathogens are prevented from entering the lower respiratory tract by cough reflex, or by the action of tracheobronchial secretions or by the mucocilliary transport of the inhaled materials from the lower respiratory tract to oropharynx or by the body's immune or non

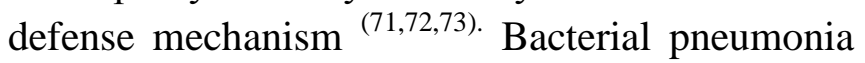
is most commonly caused by the aspiration of the oral microorganisms into the lower respiratory because of the failure of the defense mechanism against the pathogens and multiplication of the pathogens causing destruction of the tissue surface (74)

Scannopieco et al ${ }^{(75)}$ in their study showed that the patients with pneumonia have a poor oral hygiene and so the oral hygiene index score is very high when compared with persons without respiratory disease. Limeback ${ }^{(76)}$ in his research also proved that poor oral hygiene is observed in persons with aspiration pneumonia. Loesche and Lopatin ${ }^{(77)}$ have found out that the people with definite aspirational pneumonia are $3.3 \%$ more likely to have periodontitis.

\section{SARCOIDOSIS}

Sarcoidosis is a systemic disease with the presence of ganulomas in the lungs. The oral lesions in sarcoidosis are localized swelling or nodules, non tender ulcerations in the gingival, buccal and labial mucosa and palate, gingival inflammations, hyperplasia or recession. Rarely the swelling, enlargement and ulcerations are seen in tongue and salivary glands ${ }^{(78)}$. In $6 \%$ of patients the parotid gland impairment is seen, especially in females it has a tumor like appearance and with xerostomia. HeerfordtWaldenstrom syndrome includes systemic sarcoidosis, xerostomia and parotid gland swelling with bilateral uveitisand facial nerve palsy ${ }^{(79,80)}$. The maxillary and the mandibular jaw bones are equally affected, symptoms like tooth loosening radiating pain, mandibular tumefaction and maxillary bone loss are seen ${ }^{(78)}$.

\section{LUNG CARCINOMA}

Lung carcinomas affect the jaw bones more when compared to the soft tissues, of which the mandible is the most common site of metastases. About 55\% of metastases occur in the mandible. Some studies reports that the oral metastases can be the first manifestations, which unfortunately announce that the pulmonary disease is in the advance stage In the mandible the most common symptoms are progressive localized swelling, pain, paresthesia of the lower lip because the tumor invades the inferior alveolar never ${ }^{(81)}$. If the metastases occurs in the soft tissue, they present as submucosal mass, highly vascularized, often hemorrhagic, sometimes rarely ulcerations can be seen, and a hyperplastic reactive lesions (82).

\section{DRUGS TAKEN FOR PULMONARY DISEASES AND ITS ORAL MANIFESTATIONS}

Patients affected by pulmonary drugs often take inhaled medications, and a bigger portion of these inhaled medications are usually present in the oropharyngeal region. The general symptoms seen in patients taking medications for pulmonary diseases are erostomia, dental cavities, halitosis, ulcerations, candidiasis, mucosal changes, gingivitis, periodontitis, gastro-esophageal reflux (83).

Beta2-mimetic drugs which are used for asthmatic patients causes reduction in the production and secretion of saliva which in turn causes dental caries, increases the Lactobacillus sp. And Streptococcus mutans population, relaxes the 
smooth muscles of the lower esophageal sphincter causing gastro-esophageal reflux, because of the reflux the $\mathrm{pH}$ of the saliva will also decrease causing enamel demineralization. Also these inhaled drugs will contain fermentable carbohydrates which further increase the risk of dental caries. ${ }^{(64)}$

Corticosteroids are used by patients with asthma and COPD. It is usually used as inhaled medication. So a significant dosage of the drugs remains persistent in the oropharyngeal region causing topical effects like candidiasis, dysphonia, tongue hypertrophy, perioral dermatitis. Oral candidiasis lesion has characteristic features like whitish papulaes and plaques, inflamed or bleeding tissues under the lesion. A high incidence of gingivitis is also seen in some cases $(84,85,86,87)$.

\section{CONCLUSION}

This review gives some knowledge about the various pulmonary disorders and its manifestations in the oral cavity. It is necessary for the dental surgeons to know about the signs, symptoms, and presentations of the medical diseases to provide a good dental care with safety precautions so as to avoid discomfort to the patient's health, also regular oral examinations can always give a clue for the diagnosis of major systemic illness like respiratory diseases. So the oral manifestations in the pulmonary diseases are often required for early recognition of the diseases such that the patients get the ultimate benefits from it.

\section{REFERENCE}

1. Poul Erik Petersen,Denis Bourgeois, Hiroshi Ogawa, Saskia Estupinan-Day, \& Charlotte Ndiaye. The global burden of oral diseases and risks to oral health. Bulletin of the World Health Organization ,September 2005, 83 (9)

2. Oral Diseases and Other Systemic Conditions. Washington state department of health. DOH 160-001 July 2007
3. Comprehensive respiratory medicine. London: Albert R, Spiro S, Jett J. Mosby Inc.; 1999.

4. Doina-Clementina Cojocaru, Andrei Georgescu, Robert D.Negru. Oral manifestations in pulmonary diseases- too often a neglected problem. International journal of medical dentistry

5. Baltch, A. L., H. L. Pressman, C. Schaffer, R. P. Smith, M. C. Hammer, M.Shayegani, and P. Michelsen. 1988. Bacteremia in patients undergoing prophylaxis as recommended by the American Heart Association, 1977. Arch. Intern. Med. 148:1084-1088

6. Carroll, G. C., and R. J. Sebor. 1980. Dental flossing and its relationship to transient bacteremia. J. Periodontol. 51:691-692

7. Ebelian, G. J., I. Olsen, and L. Tronstad. 1995. Bacteremia in conjunction with endodontic therapy. Endod. Dent. Traumatol. 11:142-149.

8. Donley, T. G., and K. B. Donley. 1988. Systemic bacteremia following toothbrushing: a protocol for management of patients susceptible to infective endocarditis. Gen. Dent. 36:482-484.

9. Drinnan, A. J., and C. Gogan. 1990. Bacteremia and dental treatment.J. Am. Dent. Assoc. 120:378.

10. Heimdahl, A., G. Hall, M. Hedberg, H. Sandberg, P. O. Soder, K. Tuner, and C. E. Nord. 1990. Detection and quantitation by lysis-filtration of bacteremia after different oral surgical procedures. J. Clin. Microbiol. 28: 2205-2209.

11. Little, J. W. 1991. Prosthetic implants: risk of infection from transient dental bacteremia. Compendium 12:160-164.

12. Lofthus, J. E., M. Y. Waki, D. L. Jolkovsky, J. Otomo-Corgel, M. G. Newman, T. Flemmig, and S. Nachnani. 1991. Bacteremia following subgingival 
irrigation and scaling and root planing. $\mathrm{J}$. Periodontol. 62:602-607.

13. Navazesh, M., and R. Mulligan. 1995. Systemic dissemination as a result of oral infection in individuals 50 years of age and older. Spec. Care Dentist.15:11-19.

14. Okabe, K., K. Nakagawa, and E. Yamamoto. 1995. Factors affecting the occurrence of bacteremia associated with tooth extraction. Int. J. Oral Maxillofac. Surg. 24:239-242.

15. Kilian, M. 1982. Systemic disease: manifestations of oral bacteria, p. 832838. In J. R. McGhee, S. M. Michalek, and G. H. Cassell (ed.), Dental microbiology. Harpers \& Row, Philadelphia, Pa.

16. Loesche, W. J. 1994. Ecology of the oral flora, p. 307-319. In R. J. Nisengardand M. G. Newman (ed.), Oral microbiology and immunology, 2nd ed. W. B. Saunders, Philadelphia, Pa.

17. Loesche, W. J., and D. E. Lopatin. 1998. Interactions between periodontal disease, medical diseases and immunity in the older individual. Periodontol. 2000 16:80105.

18. Weinberg, A., S. Krisanaprakornkit, and B. A. Dale. 1998. Epithelial antimicrobial peptides: review and significance for oral applications. Crit. Rev. Oral Biol. Med. 9:399-414.

19. Loesche, W. J. 1994. Periodontal disease as a risk factor for heart disease. Compendium 15:976, 978-982, 985-986 passim.

20. Christensen PJ, Kutty K, Adlam RT, Taft TA, Kampschroer BH. Septic pulmonary embolism due to periodontal disease. Chest 1993; 104(6):1927-9.

21. Morris JF, Sewell DL. Necrotizing pneumonia caused by mixed infection with Actinobacillus actinomycetemcomitans and Actinomyces israelii: case report and review. Clin Infect Dis 1994; 18(3):450-2.

22. Huxley EJ, Viroslav J, Gray WR, Pierce AK. Pharyngeal aspiration in normal adults and patients with depressed consciousness. Am J Med 1978; 64(4):564-8.

23. Philippe Mojon, DMD, PhD, Oral Health and Respiratory Infection. Journal of the Canadian Dental Association. June 2002, Vol. 68, No. 6

24. Haslett C, Chilvers ER, Corris P.A. Respiratory disease IN: Haslett christoper, Chilvers Edwin R, Boon Nicholas A, Colledge Nicki R. Davidson's principles and practice of medicine I9th ed. Churchill living stone: Edinburgh; 2002 : 508-513.

25. Dental Recommendations for Preventing Complications in Patients with Chronic Conditions Health Partners Research Foundation eDent Study.

26. SS,Rahman, M.Faruque, MHAKhan, SAHossain. Dental management of COPD patient.Bang Med J (Khulna) 2011; 44 : 21-24

27. Russell SL, Boylan RJ, Kaslick RS, Scannapieco FA, Katz RV.Respiratory pathogen colonization of the dental plaque of institutionalized elders. Spec Care Dentist 1999;19:128-34.

28. Scannapieco FA, Papandonatos GD, Dunford RG. Associations between oral conditions and respiratory disease in a national sample survey population. Ann Periodontol 1998;3:251-6.

29. Scannapieco FA, Ho AW. Potential associations between chronic respiratory disease and periodontal disease: analysis of national health and nutrition examination survey III. J Periodontol 2001;72:50-6

30. Hayes C, Sparrow D, Cohen M, Vokonas PS, Garcia RI. The association between alveolar bone loss and pulmonary function:the VA dental longitudinal study. Ann Periodontol 1998;3:257-61.

31. Persson GR, Ohlsson O, Pettersson T, Renvert S. Chronic periodontitis, a significant relationship with acute 
myocardial infarction. Eur Heart $\mathbf{J}$ 2003;24:2108-15.

32. Renvert S, Ohlsson O, Persson S, Lang NP, Persson GR. Analysis of periodontal risk profiles in adults with or without a history of myocardial infarction. J Clin Periodontol 2004;31:19-24.

33. Leuckfelda, M.V. Obregon-Whittlea, M.B. Lundb, O. Geiranc, Ø. Bjørtuftb, I. Olsena. Severe chronic obstructive pulmonary disease: Association with marginal bone loss in periodontitis. Respiratory Medicine (2008) 102, 488-494.

34. Leuckfeld I, Obregon-Whittle MV, Lund MB, Geiran O, Bjørtuft $\varnothing$, Olsen I. Severe chronic obstructive pulmonary disease: association with marginal bone loss in periodontitis. Respir Med 2008; 102: 488494.

35. Hyman JJ, Reid BC. Cigarette smoking, periodontal disease: and chronic obstructive pulmonary disease. J Periodontol 2004; 75: 9-15.

36. Wang Z, Zhou X, Zhang J, Zhang L, Song Y, Hu FB, Wang C. Periodontal health, oral health behaviours, and chronic obstructive pulmonary disease. J Clin Periodontol 2009; 36: 750-755.

37. Przybylowska D, Mierzwiñska-Nastalska E, Rubinsztajn R, Chazan R, Rolski D, Swoboda-Kopeæ E. Influence of denture plaque biofilm on oral mucosal membrane in patients with chronic obstructive pulmonary disease. Adv Exp Med Biol 2015; 839: 25-30.

38. Kornum JB, Svaerke C, Thomsen RW, Lange $\mathrm{P}$, Sorensen HT. Chronic obstructive pulmonary disease and cancer risk: a Danish nationwide cohort study. Respir Med 2012; 106: 845-852.

39. Kolokotronis A, Antoniadis D, Trigonidis G, Papanagiotou P. Oral tuberculosis: Oral Dis 1996;2:242-3.
40. Mignogna MD, Muzio LLO, Favia G, et al.( 2000) Oral tuberculosis: a clinical evaluation of 42 cases. Oral Dis 6:25-30

41. Sezer B, Zeytinoglu M, Tuncay U, Unal T (2004) Oral mucosal ulceration: a manifestation of previously undiagnosed pulmonary tuberculosis. J Am Dent Assoc 135:336-40.

42. Hashimoto Y, Tanioka H (1989) Primary tuberculosis of the tongue: report of a case. J Oral Maxillofac Surg 47:744-46.

43. Aoun N, El-Haji G, El Toum S. Oral ulcer: an uncommon site in primary tuberculosis. Austral Dent J 2015; 60(1): 119

44. Singhaniya SB, Barpande SR, Bhavthankar JD. Oral tuberculosis in an asymptomatic pulmonary tuberculosis. Oral Surg Oral Med Oral Pathol Oral Radiol Endod 2011; 111(3): e8-e10.

45. Sezer B, Zeytinoglu M, Tuncay U, Unal T. Oral mucosal ulceration: a manifestation of previously undiagnosed pulmonary tuberculosis. J Am Dent Assoc 2004; 135(4): 336-340.

46. Tubercular Palatal Perforation : First Clinical Sign of Undiagnosed Pulmonary Tuberculosis. Volume : 3 Issue : 8 Aug 2013 , ISSN - 2249-555X

47. Kamala R, Abhishek Sinha, Amitabh Srivastava1, Sunita Srivastava. Primary tuberculosis of the oral cavity. May 08, 2016, IP: 117.208.201.24

48. P. Mahesh Kumar , Capt. S. Manoj Kumar, Sonali Sarkar, S. Ramasubramanian, K.J.Anu, L.Aravindh. Oral manifestations in patients with pulmonary tuberculosis. 2010 Bio Med Sci Direct Publications IJBMR -ISSN: 0976:6685

49. Ferrazzano GF, Orlando S, Sangianantoni $\mathrm{G}$, Cantile $\mathrm{T}$, Ingenito A. Dental and periodontal health status in children affected by cystic fibrosis in a southern Italian region. Eur J Ped Den 2009; 10(2): 65-68. 
50. Gerald W. Fernald, MD Michael W. Roberts, DDS, MScD Thomas F. Boat, MD. Cystic fibrosis: a current review. PEDIATRICD ENTISTRY/Copyrigh@t 1990 by The AmericanA cademoy $f$ Pediatric Dentistry Volume 12, Number 2.

51. Swallow JN, DeHaller J, Young WF: Sideeffects to antibiotics in cystic fibrosis: dental changes in relation to antibiotic administration. Arch Dis Child 42:311-18, 1967.

52. Jagels AE, Sweeney EA: Oral health of patients with cystic fibrosis and their siblings. J Dent Res 55:991-96, 1976.

53. Mandel ID, Kutcher A, Denning CR, Thompson RH, Zegarelli EV: Salivary studies in cystic fibrosis. Am I Dis Child 113:431-38,1967.

54. Wiesmann UN, Boat TF, di Sant'Agnese PA: Flow-rates and electrolytes in minor salivary-gland saliva in normal subjects and patients with cystic fibrosis. Lancet II:510-12, 1972.

55. Wotman S, Mercadante J, Mandel ID, Goldman RS, Denning C: The occurance of calculus in normal children, children with cystic fibrosis, and children witb asthma. J Periodonto144:278-80, 1973.

56. Kinirons M J: Dental health of children with cystic fibrosis: an interim report. J Paediatr Dent 1:3-7, 1985.

57. Primosch RE: Tetracycline discoloration, enamel defects and dental caries in patients with cystic fibrosis. Oral Surg 50:301-308, 1980.

58. Littleton NW, White CL: Dental findings from a preliminary study of children receiving extended antibiotic therapy. J Am Dent Assoc 68:520-25, 1964.

59. Sweeney EA, Shaw IA: The effect of dietary pancreatin supplements on dental caries and on the composition of saliva in caries susceptible rats. J Dent Res 44:97376, 1965.
60. Lindemann RA, Newman MG, Kaufman AK, LeTV: Oral colonization and susceptibility testing of Pseudomonas aeruginosa oral isolates from cystic fibrosis patients. J Dent Res 64:54-57, 1985.

61. Blacharsh C: Dental aspects of patients with cystic fibrosis: a preliminary clinical study. J Am Dent Assoc 95:106-110, 1977.

62. ICD 9 code 493.2

63. Thomas MS, Parolia A, Kundabala M, Vikram M. Astma and oral health: a review. Austral Dent J 2010; 55: 128-133. doi: 10.1111/j.1834- 7819.2010.001226.x

64. Ryberg M, Moller C, Ericson T. Saliva composition and caries development in asthmatic patients treated with beta-2 adrenoceptor agonists: a 4-year follow-up study. Scand J Dent Res 1991; 99: 212218.

65. Kuo LC, Polson AM, Kang T. Associations between periodontal diseases and systemic diseases: a review of the inter-relationships and interactions with diabetes, respiratory diseases, cardiovascular diseases and osteoporosis. Public Health 2008; 12: 417-433.

66. Stensson M, Wendt LK, Koch G, Oldaeus G, Birkhed D. Oral health in preschool children with asthma. Int $\mathbf{J}$ Paediatr Dent 2008; 18: 243-250.

67. Arbes SJ, Matsui EC. Can oral pathogens influence allergic disease? J Allergy Clin Immunol 2011; 127: 1119-1127.

68. Card JW, Carey MA, Voltz JW, Bradbury A, Ferguson CD, Cohen EA, Schwartz S, Flake GP, Morgan DL, Arbes SJ, Barrow DA, Barros SP, Offenbacher S, Zeldin DC. Modulation of allergic airway inflammation bt the oral pathogen Porphyromonas gingivalis. Infect Immunol 2010; 78(6): 2488-2496. doi:10.1128/IAI.01270-09

69. Arbes SJ Jr, Sever ML, Vaughn B, Cohen EA, Zeldin DC. Oral pathogens and 
allergic disease: results from the Third National Health and Nutrition Examination Survey. J Allergy Clin Immunol 2006; 118: 1169-1175.

70. Xiaojing LI, Krishtin M, Kolltveit, Leif Tronstad and Ingar Olsen. Systemic Diseases Caused by Oral Infection. Clinical microbiological review, 0893$8512 / 00 / \$ 04.0010$ Oct. 2000 , p. $547-558$ Vol. 13, No. 4

71. Donowitz, G. R., and G. L. Mandell. 1990. Acute pneumonia, p. 540-555. In G. L. Mandell, R. G. Douglas, and J. E. Bennett (ed.), Principles and practice of infectious diseases. Churchill Livingstone, New York, N.Y.

72. Levison, M. E. 1994. Pneumonia, including necrotizing pulmonary infections (lung abscess), p. 1184-1191. In K. J. Isselbacher, E. Braunwald, and J. D. Wilson (ed.), Harrison's principles of internal medicine. McGraw-Hill, New York, N.Y.

73. Scannapieco, F. A., and J. M. Mylotte. 1996. Relationships between periodontal disease and bacterial pneumonia. J. Periodontol. 67:1114-1122.

74. Bonten, M. J., C. A. Gaillard, F. H. van Tiel, H. G. Smeets, S. van der Geest, and E. E. Stobberingh. 1994. The stomach is not a source for colonization of the upper respiratory tract and pneumonia in ICU patients. Chest 105:878-884.

75. Scannapieco, F.A. G.D.Papandonatos, and R. G. Dunford. 1998. Associations between oral conditions and respiratory disease in a national sample survey population. Ann. Periodontol. 3:251-256.

76. Limeback, H. 1988. The relationship between oral health and systemic infections among elderly residents of chronic care facilities. Gerodontology 7:131-137.
77. Loesche, W. J., and D. E. Lopatin. 1998. Interactions between periodontal disease, medical diseases and immunity in the older individual. Periodontol. 2000 16:80 105.

78. Suresh L, Radfar L. Oral sarcoidosis: a review of literature. Oral Diseases 2005; 11: 138-145.

79. James DG, Sharma OP. Parotid gland sarcoidosis. Sarcoidosis Vasc Diffuse Lung Dis 2000; 17: 27-32.

80. Mandel L, Kaynar A. Sialadenopathy: a clinical herald of sarcoidosis. J Oral Maxillofac Surg 1994; 52: 1208-1210.

81. Kaugars GE, Svirsky JA. Lung malignancies metastatic to the oral cavity. Or Surg Or Med Or Pa 1981; 51(2): 179-186.

82. Maiorano E, Piatelli A, Favia G. Hepatocellular carcinoma metastatic to the oral mucosa: report of a case with multiple gingival localizations. J Periodontal 2000; 71: 641-645.

83. Godara N, Godara R, Khullar M. Impact of inhalation therapy on oral health. Lung India 2011; 28: 272-275.

84. Buhl R. Local oropharyngeal side effects of inhaled corticosteroids in patients with asthma. Allergy 2006; 61: 518-526.

85. Kelly HW, Nelson HS. Potential adverse effects of the inhaled corticosteroids. J Allergy Clin Immunol 2003; 112: 469478.

86. Casiglia JM, Elston DM. Oral manifestations of systemic diseases. Medscape reference, http://emedicine.medscape.com/article/1081029overview, Accessed October 6, 2014.122

87. McDerra EJ, Bjerkeborn K, Dahllof G, Hedlin G, Lindell M, Modeer T. Effect of disease severity and pharmacotherapy of asthma on oral health in asthmatic children. Scand J Dent Res 1988; 22: 297-301. 